\title{
Secondary Focal Segmental Glomerulosclerosis in an Adolescent Born with a Very Low Birth Weight
}

\author{
Yoshinobu Fuke, Yusuke Murata, Seiichiro Hemmi, Mamiko Kajiwara, Minako Yabuki, \\ Takayuki Fujita and Masayoshi Soma
}

\begin{abstract}
A 17-year-old man presented with a decreased renal function (creatinine clearance $66.0 \mathrm{ml} / \mathrm{min} / 1.73 \mathrm{~m}^{2}$ ) and proteinuria $(1.25 \mathrm{~g} / 24 \mathrm{hrs})$. He was born weighing 1,065 g 26 weeks of pregnancy. He was mildly overweight (BMI $\left.26.9 \mathrm{~kg} / \mathrm{m}^{2}\right)$ due to an increased weight gain $(10 \mathrm{~kg})$ over the past year. Renal biopsy showed perihilar sclerosing lesions in three of eleven glomeruli, low glomerular density, enlarged glomeruli, and limited fusions of foot processes, thus indicating secondary focal segmental glomerulosclerosis (FSGS). We speculated that the patient's overweight status may have caused a worsening of glomerular hyperfiltration due to the fewer number of nephrons leading to the development of secondary FSGS.
\end{abstract}

Key words: very low birth weight, secondary focal segmental glomerulosclerosis, overweight status

(Intern Med 53: 2233-2236, 2014)

(DOI: 10.2169/internalmedicine.53.2552)

\section{Introduction}

Low birth weight (LBW), resulting from intrauterine growth retardation (IUGR) or prematurity, is a risk factor for various adult diseases, including hypertension, coronary heart disease, diabetes, stroke and chronic kidney disease $(1,2)$. Several epidemiological studies have shown an association between LBW and end-stage renal disease (ESRD) or renal failure in late adulthood $(3,4)$, although the causal pathway remains unknown.

No differences were found in the renal function and proteinuria of pre-school children between those born at very preterm (born before gestational 32 weeks) and those born at term with an appropriate birth weight for gestational age (5). Keijzer-Veen et al. (6) showed that birth weight was negatively associated with serum creatinine concentration, positively with glomerular filtration rate (GFR), and negatively with the logarithm of albumin-creatinine ratio (ACR) in 422 19-year-old subjects born at very preterm. However, all subjects had a normal renal function, and the prevalence of microalbuminuria (ACR $>2.2 \mathrm{mg} / \mathrm{mmoL}$ ) was only $2.7 \%$. Therefore, subjects before young-adult age who were born with a very LBW do not appear to have significant renal in- juries.

We herein describe a 17 -year-old man born preterm with a very LBW presenting with hypertension, distinct proteinuria and moderate decreased renal function.

\section{Case Report}

A 17-year-old man was referred to our hospital due to the onset of distinct proteinuria, which was detected at a school urinary screening this year. Until the age of 16 , no urinary abnormality had ever been pointed out at a school urinary screening. He was a twin born weighing 1,065 g 26 weeks of pregnancy which resulted in an intrauterine fetal demise of one twin without twin-to-twin transfusion syndrome (TTTS). His growth and development were normal. He gained $10 \mathrm{~kg}$ of weight this past year, resulting in mild overweight status (BMI $26.9 \mathrm{~kg} / \mathrm{m}^{2}$ ). There was no other medical history or family history of renal diseases.

Physical examination showed the following: height, 159.0 cm; weight, $68.0 \mathrm{~kg}$; BMI, $26.9 \mathrm{~kg} / \mathrm{m}^{2}$; blood pressure, 144/ $78 \mathrm{mmHg}$; pulse rate, 76 beats/min; and temperature, 36.3 ${ }^{\circ} \mathrm{C}$. No abnormalities were found in other physical examinations.

Urinalysis revealed (2+) proteinuria but (-) hematuria with 

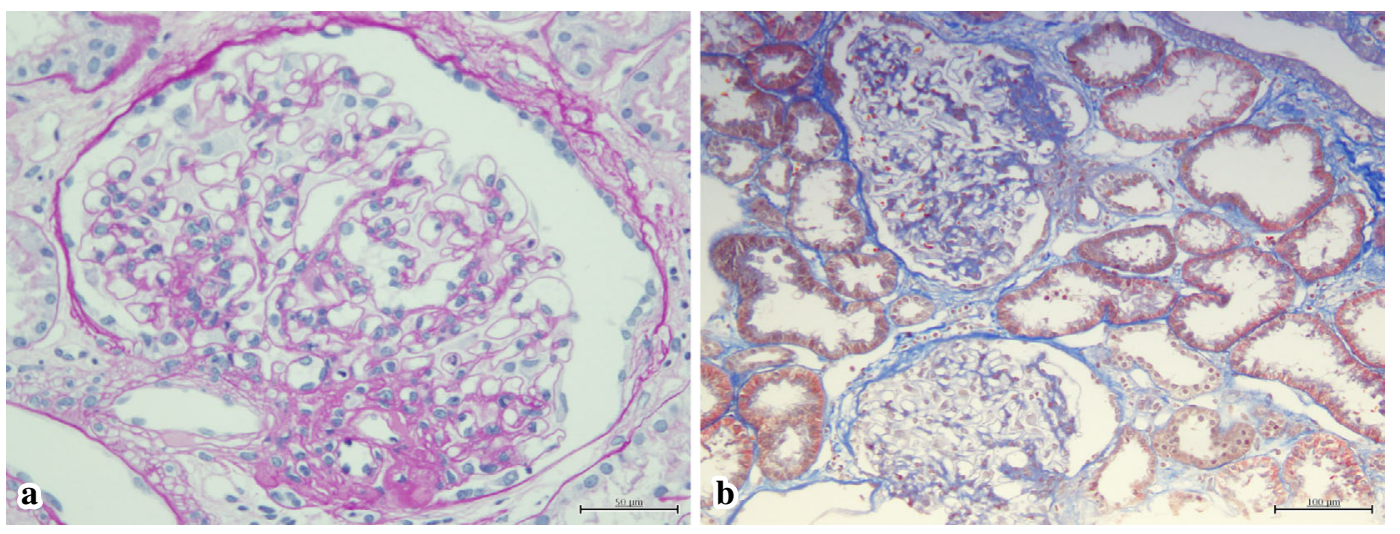

Figure 1. Light microscopy showing expanded glomeruli with perihilar segmentally sclerosing lesions. (a) PAS staining (magnification 400x). (b) Masson-T staining (magnification 200x).

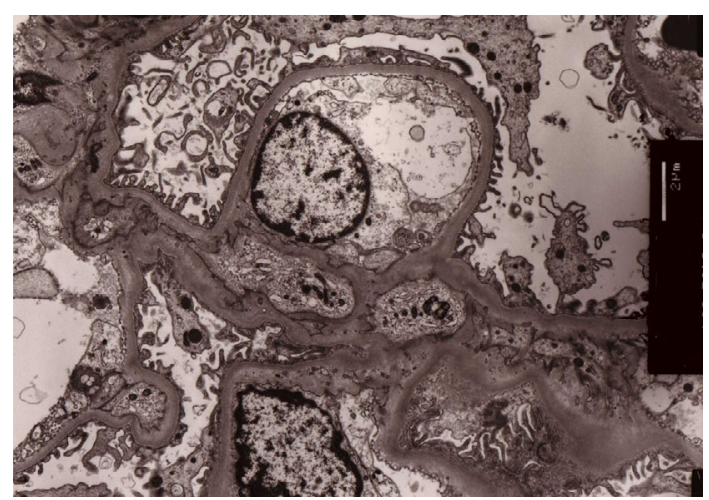

Figure 2. Electron microscopy showing limited fusions of foot processes (original magnification $7500 \times$ ).

dipstick. A 24-hr urine collection revealed $1.25 \mathrm{~g}$ of protein. Urinary $\beta 2-M G$ (beta2-microglobulin) level was $93 \mu \mathrm{g} / \mathrm{L}$ (normal $<200 \quad \mu \mathrm{g} / \mathrm{L})$, and NAG (N-acetyl-beta-Dglucosaminidase activity) level was below $5.0 \mathrm{U} / \mathrm{L}$. The serum creatinine level was $1.13 \mathrm{mg} / \mathrm{dL}$ (normal $0.70-1.30 \mathrm{mg} /$ $\mathrm{dL})$ and creatinine clearance moderately decreased to 66.0 $\mathrm{ml} / \mathrm{min} / 1.73 \mathrm{~m}^{2}$. On ultrasonography, both kidneys were somewhat smaller (the longitudinal diameters of kidneys were $8.8 \mathrm{~cm}$ for the right kidney and $9.5 \mathrm{~cm}$ for the left kidney) with normal cortical thicknesses.

A percutaneous renal biopsy from the left kidney was performed to establish a diagnosis. On microscopy, the specimen contained eleven glomeruli, three of which had perihilar segmental sclerosing lesions (Fig. 1). The mean diameter of the glomeruli had expanded to $242.2 \mu \mathrm{m}$, which was larger than normal glomeruli $(168 \pm 12 \mu \mathrm{m})(7)$. The glomerular number per renal cortical area was $1.92 / \mathrm{mm}^{2}$, which was less than the normal glomerular density $(3.2 \pm 1.2 /$ $\left.\mathrm{mm}^{2}\right)(8)$. Interstitial fibrosis and atrophy of the tubules were partially observed. There was a small artery with mild intimal hyalinization. Immunofluorescence was negative for $\mathrm{IgM}, \mathrm{IgG}, \mathrm{IgA}, \mathrm{C} 1 \mathrm{q}, \mathrm{C} 4, \mathrm{C} 3$ and fibrinogen. Electron micrographs showed limited fusions of foot processes (Fig. 2).

After the diagnosis, the patient lost weight $13 \mathrm{~kg}$, and urinary protein excretion decreased to 0.4 (urinary protein/uri- nary creatinine rate) after 6 months.

\section{Discussion}

Nephrogenesis begins in the 9th week of gestation and continues up to the 36th week with particularly rapid development during the last trimester. New nephrons are not formed after birth except in the case of extremely preterm infants, in whom nephrogenesis ceases approximately $40 \mathrm{~d}$ after birth (9). Therefore, the nephron number is dependent on both normal intrauterine environment and the gestational age at birth.

Epidemiological studies have shown a LBW to be associated with hypertension and an impaired renal function in adulthood $(1,2)$. Brenner and colleagues (10) postulated that retraction of renal development, as occurs in individuals of LBW, gives rise to increased postnatal risks for systemic and glomerular hypertension. Autopsy studies have found direct correlations between a LBW and a reduced nephron number and expanded glomerular size $(11,12)$, thus indicating that a reduced nephron number in a very LBW case might be severe. Moreover, a very LBW with postnatal acute renal failure showed a low glomerular supply and clear evidence of active glomerulosclerosis (13). Therefore, the glomeruli adapt through hypertrophy and glomerular hypertension, probably leading to progressive glomerulosclerosis and a decline in the renal function when the response becomes maladaptive. However, until now, the occurrence of secondary focal segmental glomerulosclerosis (FSGS) has been reported in only two adolescents born with a very LBW (14).

Hodgin et al. (14) reported two adolescents with histories of a very LBW, a 15-year-old boy born weighing 1,400 $\mathrm{g}$ at 23 weeks of pregnancy and a 17-year-old boy born weighing $600 \mathrm{~g}$ at 24 weeks of pregnancy. They were not obese with (BMI 21 and $25.4 \mathrm{~kg} / \mathrm{m}^{2}$, respectively). The 24-hr urine protein was $2 \mathrm{~g}$ and $1.3 \mathrm{~g}$, respectively; and serum creatinine levels were both $0.9 \mathrm{mg} / \mathrm{dL}$. Renal biopsies of the two patients revealed FSGS involving a minority of glomeruli with a predominance of perihilar lesions of sclerosis, 
glomerulomegaly $(275 \pm 21 \mu \mathrm{m}$ and $207 \pm 14 \mu \mathrm{m}$ of mean glomerular diameter, respectively), and only mild foot process effacement, all features typical of secondary (adaptive) FSGS. In addition, the latter had mesangial cells positive for IgA according to immunofluorescence studies.

Secondary (adaptive) FSGS to structural-functional adaptation is a pattern of injury mediated by an elevated glomerular capillary pressure and flow rates that occur as an adaptive response to increased hemodynamic stress (15). The pathological features have discrete segmental scars, involving the perihilar regions of hypertrophied glomeruli, and the degree of foot process fusion is generally milder compared to primary FSGS, affecting less than $50 \%$ of the total glomerular capillary surface area (16). In addition, patients with secondary FSGS usually manifest proteinuria in the absence of full nephrotic syndrome. Therefore, in this case, the clinical-pathologic features were diagnostic of secondary (adaptive) FSGS.

Oligomeganephronia (OMN) is a congenital anomaly of bilateral renal hypoplasia. The most frequently affected patients develop progressive renal insufficiency, leading to end-stage renal failure (ESRF), either in early childhood or early-mid adolescence. Adult OMN has only been reported in a few patients, and those who do not advance to ESRF present with secondary FSGS $(17,18)$. Clinical and renal pathological features of such patients appear to be similar to our case. OMN is not usually related to a very LBW, but it is accompanied with bilateral small kidneys. Pathologically, marked compensatory hypertrophy of proximal tubules and glomeruli is observed (19). These features might be useful to distinguish renal impairment of OMN from a very LBW.

Hodgin et al. (14) advocated a "two-hit" hypothesis for the pathogenesis of secondary FSGS, which proposes that the low nephron number (first hit) may influence the presentation and modify the course of a subsequent renal injury (second hit). Indeed, a LBW may be associated with a worse outcome in diverse renal diseases, including idiopathic membranous nephropathy, minimal change disease, and $\operatorname{IgA}$ nephropathy $(14,20-22)$. In this case, the mild overweight status (second hit) might have caused a worsening of glomerular hyperfiltration with the lower nephron number (first hit), thus leading to the secondary FSGS.

Emerging epidemiological evidence has indicated that an overweight status and obesity are risk factors for chronic kidney disease (CKD) and ESRD (23-25). The renal effect of obesity in experimental animals and humans include both structural and functional adaptations, such as an increased GFR, increased renal blood flow, and renal hypertrophy $(26,27)$. In this case, urinary protein excretion appeared, followed by a $10 \mathrm{~kg}$ weight gain. Recently, Kataoka et al. (28) showed a BMI $\geq 25 \mathrm{~kg} / \mathrm{m}^{2}$ to be an independent predictor of disease progression in IgA nephropathy, suggesting that even a mild overweight status might contribute to a progression of renal injury in the setting of renal impairment.

Abitbol et al. (29) examined the relative risk of obesity and very preterm birth ( $\leq 32$ weeks of gestational age) on the progression of kidney disease. This study showed that, in obese children born at very preterm, kidney disease was two-times more likely to advance to ESRD than in obese patients born at term ( $>36$ weeks of gestational age) and five-times more likely to progress than in non-obese, very preterm children. These results indicate that obesity appears to be a more important modifiable risk factor in the development and progression of renal disease in children born very preterm than at term.

On ultrasonography, left kidney length was larger than right kidney, and renal tissue was obtained from the left kidney. Keijzer-Veen et al. (30) reported the left kidney length and volume to be significantly lower in very preterm individuals ( $<32$ weeks of gestational age), most notably in women. In $40-50 \%$ of the individuals, however, the left kidney was larger than the right kidney. Kidney volume is thought to be directly related to the number of nephrons, and therefore volumetric estimation of the kidney by ultrasound is an indirect measurement of the number of functional units in the kidney (31). Therefore, the right kidney might have severe renal impairment compared to the left kidney, resulting from a greater reduction of nephron number and glomerular enlargement with glomerulosclerosis.

This is a very rare case of secondary FSGS in an adolescent born with a very LBW. Although the etiology could not be clearly defined, several mechanisms, such as a severely reduced nephron number with a very LBW, an increased degree of hypoplasia of the right kidney, and rapid weight gain may have played a role in the onset of marked glomerular hyperfiltration. We therefore speculate that the mild overweight status may lead to a worsening of glomerular hyperfiltration with the lower nephron number, thus leading to secondary FSGS.

The authors state that they have no Conflict of Interest (COI).

\section{References}

1. Barker DJ, Osmond C, Simmonds SJ, Wield GA. The relation of small head circumference and thinness at birth to death from cardiovascular disease in adult life. BMJ 306: 422-426, 1993.

2. Barker DJ. Adult consequences of fetal growth restriction. Clin Obstet Gynecol 49: 270-283, 2006.

3. Lackland DT, Bendall HE, Osmond C, Egan BM, Barker DJ. Low birth weights contribute to high rates of early-onset chronic renal failure in the Southeastern United States. Arch Intern Med 160: 1472-1476, 2000.

4. Dyck R, Klomp H, Tan L, Stang MR. An association of maternal age and birth weight with end-stage renal disease in Saskatchewan. Sub-analysis of registered Indians and those with diabetes. Am J Nephrol 23: 395-402, 2003.

5. Rakow A, Johansson S, Legnevall L, et al. Renal volume and function in school-age children born preterm or small for gestational age. Pediatr Nephrol 23: 1309-1315, 2008.

6. Keijzer-Veen MG, Schrevel M, Finken MJ, et al; Dutch POPS-19 Collaborative Study Group. Microalbuminuria and lower glomerular filtration rate at young adult age in subjects born very premature and after intrauterine growth retardation. J Am Soc Nephrol 
16: $2762-2768,2005$.

7. Kambham N, Markowitz GS, Valeri AM, Lin J, D’Agati VD. Obesity-related glomerulopathy: an emerging epidemic. Kidney Int 59: 1498-1509, 2001

8. Tsuboi N, Utsunomiya Y, Kanzaki G, et al. Low glomerular density with glomerulomegaly in obesity-related glomerulopathy. Clin J Am Soc Nephrol 7: 735-741, 2012.

9. Rodríguez MM, Gómez AH, Abitbol CL, Chandar JJ, Duara S, Zilleruelo GE. Histomorphometric analysis of postnatal glomerulogenesis in extremely preterm infants. Pediatr Dev Pathol 7: 17-25, 2004

10. Brenner BM, Chertow GM. Congenital oligonephropathy and the etiology of adult hypertension and progressive renal injury. Am J Kidney Dis 23: 171-175, 1994.

11. Hughson MD, Douglas-Denton R, Bertram JF, Hoy WE. Hypertension, glomerular number, and birth weight in African Americans and white subjects in the southeastern United States. Kidney Int 69: 671-678, 2006.

12. Mañalich R, Reyes L, Herrera M, Melendi C, Fundora I. Relationship between weight at birth and the number and size of renal glomeruli in humans: a histomorphometric study. Kidney Int $\mathbf{5 8}$ 770-773, 2000.

13. Rodríguez MM, Gómez AH, Abitbol CL, Chandar JJ, Duara S, Zilleruelo GE. Histomorphometric analysis of postnatal glomerulogenesis in extremely preterm infants. Pediatr Dev Pathol 7: 17-25, 2004

14. Hodgin JB, Rasoulpour M, Markowitz GS, D’Agati VD. Very low birth weight is a risk factor for secondary focal segmental glomerulosclerosis. Clin J Am Soc Nephrol 4: 71-76, 2009.

15. Rennke HG, Klein PS. Pathogenesis and significance of nonprimary focal andsegmental glomerulosclerosis. Am J Kidney Dis 13: 443-456, 1989.

16. D'Agati V. Pathologic classification of focal segmental glomerulosclerosis. Semin Nephrol 23: 117-134, 2003.

17. Fuke Y, Hemmi S, Kajiwara M, Yabuki M, Fujita T, Soma M. Oligomeganephronia in an adult without end stage renal failure. Clin Exp Nephrol 16: 325-328, 2012.

18. Kawanishi K, Takei T, Kojima C, et al. Three cases of late-onset oligomeganephronia. NTD plus 4: 14-16, 2011.

19. Fetterman GH, Habib R. Congenital bilateral oligonephronic renal hypoplasia with hypertrophy of nephron (oligomeganephronia). Am J Cli Pathol 52: 199-207, 1969.

20. Duncan RC, Bass PS, Garrett PJ, Dathan JR. Weight at birth and other factors influencing progression of idiopathic membranous nephropathy. Nephrol Dial Transplant 9: 875, 1994.

21. Zidar N, Avgustin Cavić M, Kenda RB, Ferluga D. Unfavorable course of minimal change nephrotic syndrome in children with intrauterine growth retardation. Kidney Int 54: 1320-1323, 1998.

22. Zidar N, Cavić MA, Kenda RB, Koselj M, Ferluga D. Effect of intrauterine growth retardation on the clinical course and prognosis of IgA glomerulonephritis in children. Nephron 79: 28-32, 1998.

23. Wang Y, Chen X, Song Y, Caballero B, Cheskin LJ. Association between obesity and kidney disease: a systematic review and meta-analysis. Kidney Int 73: 19-33, 2008.

24. Liu H, Shi H, Yu J, Chen F, Jiang Q, Hu D. Obesity and chronic kidney disease in patients with chronic heart failure: an insight from the China Heart Survey. Clin Exp Nephrol 15: 522-528, 2011.

25. Hsu CY, McCulloch CE, Iribarren C, Darbinian J, Go AS. Body mass index and risk for end-stage renal disease. Ann Intern Med 144: 21-28, 2006.

26. Chagnac A, Weinstein T, Korzets A, Ramadan E, Hirsch J, Gafter U. Glomerular hemodynamics in severe obesity. Am J Physiol Renal Physiol 278: F817-F822, 2000.

27. Kasiske BL, Napier J. Glomerular sclerosis in patients with massive obesity. Am J Nephrol 5: 45-50, 1985.

28. Kataoka H, Ohara M, Shibui K, et al. Overweight and obesity accelerate the progression of IgA nephropathy: prognostic utility of a combination of BMI and histopathological parameters. Clin Exp Nephrol 16: 706-712, 2012.

29. Abitbol CL, Chandar J, Rodríguez MM, et al. Obesity and preterm birth: additive risks in the progression of kidney disease in children. Pediatr Nephrol 24: 1363-1370, 2009.

30. Keijzer-Veen MG, Devos AS, Meradji M, Dekker FW, Nauta J, van der Heijden BJ. Reduced renal length and volume 20 years after very preterm birth. Pediatr Nephrol 25: 499-507, 2010.

31. Nyengaard JR, Bendtsen TF. Glomerular number and size in relation to age, kidney weight, and body surface in normal man. Anat Rec 232: 194-201, 1992.

(C) 2014 The Japanese Society of Internal Medicine http://www.naika.or.jp/imonline/index.html 